\title{
A NEW RANKING APPROACH AND ITS APPLICATION TO SOLVING FUZZY CRITICAL PATH PROBLEMS
}

\author{
P. Kaur $^{1 *}$ \& A. Kumar ${ }^{2}$ \\ ${ }^{1,2}$ School of Mathematics and Computer Applications \\ Thapar University, Patiala, India \\ 1 parmpreetsidhu@gmail.com; ${ }^{2}$ amit_rs_iitr@yahoo.com
}

\begin{abstract}
There are several methods for solving fuzzy critical path problems in which ranking approaches are used to compare fuzzy numbers. In this paper, some fuzzy critical path problems are chosen to show that the results obtained with fuzzy critical path methods that use existing ranking approaches are not appropriate according to real life situations. To obtain appropriate results, a new ranking approach the Mehar ranking approach, is proposed for comparing LR flat fuzzy numbers. To show the advantages of the Mehar ranking approach over existing approaches, selected fuzzy critical path problems are solved by using the existing methods together with the Mehar ranking approach. It is shown that the obtained results are appropriate.
\end{abstract}

\section{OPSOMMING}

Daar bestaan verskeie metodes om wasige kritieke padprobleme op te los wat rangordening toepassings gebruik om wasige getalle te vergelyk. In dié artikel word 'n paar wasige kritieke padprobleme gekies om te bewys dat die resulte verkry met die wasige kritieke padmetode, wat bestaande rangordening benaderings gebruik, nie voldoende is volgens lewenswerklike voorbeelde nie. Om gepaste resultate te kry word ' $n$ nuwe rangordening benadering, die 'Mehar rangordening benadering', voorgestel om LR plat, wasige getalle te vergelyk. Om die voordele van die Mehar benadering te wys word geselekteerde probleme opgelos met beide bestaande metodes en die Mehar rangordening benadering. Die resultate bewys dat die verkreë resultate gepas is.

\footnotetext{
${ }^{1}$ The author is enrolled for a PhD (Mathematics) degree in the School of Mathematics and Computer Applications, Thapar University, Patiala, India.

* Corresponding author.
} 


\section{INTRODUCTION}

The theory of fuzzy sets was first introduced by Zadeh [24]. Since then, the theory of fuzzy sets has been applied in many fields such as pattern recognition, control theory, management sciences, and picture processing. In the field of fuzzy mathematics, many mathematical theories - such as fuzzy optimisation, fuzzy topology, fuzzy logic, fuzzy analysis, and fuzzy algebra - are obtained. In many applications of fuzzy set theory to decision-making, there is a need to select the best from a collection of possible solutions.

In the selection process there is a need to compare fuzzy numbers. Since fuzzy numbers are represented by possibility distributions, they can overlap with one another, making it difficult to determine clearly whether one fuzzy number is larger or smaller than another.

Many authors have proposed ranking approaches to the comparison of fuzzy numbers [11, $21,17,15,7,23,8,1,3,25,2,9]$. Until now, there has not been a single unifying ranking approach to the comparison of fuzzy numbers.

Several authors $[18,22,4,13,14,16,12,10,5,6,19]$ have proposed fuzzy critical path methods that are based on different ranking approaches for solving fuzzy critical path problems. In this paper, certain fuzzy critical path problems are chosen to show that the results obtained by using the existing fuzzy critical path methods with existing ranking approaches are not appropriate according to real life situations. To obtain appropriate results for fuzzy critical path problems, a new ranking approach named 'Mehar's' is proposed for comparing LR flat fuzzy numbers. To show the advantages of Mehar's ranking over existing approaches, the chosen fuzzy critical path problems are solved by using the existing fuzzy critical path methods along with Mehar's ranking approach. It is shown that the results are appropriate.

This paper is organised as follows. In Section 2, some existing ranking approaches for comparing fuzzy numbers are presented. The shortcomings of these approaches are discussed in Section 3. In Section 4, a new approach, Mehar's ranking approach, is proposed for comparing LR flat fuzzy numbers. Some important results, which are used for proposing the new ranking approach to the comparison of LR flat fuzzy numbers, are proved in Section 5. The advantages of Mehar's ranking approach over existing approaches are discussed in Section 6. In Section 7, conclusions and future work are presented.

\section{COMPARISON OF FUZZY NUMBERS}

An efficient approach for comparing fuzzy numbers is to use a ranking function $\mathfrak{R}: F(R) \rightarrow R$, where $F(R)$ is a set of fuzzy numbers defined on a set of real numbers, which maps each fuzzy number on to the real line where a natural order exists.

Let $\tilde{A}$ and $\tilde{B}$ be two fuzzy numbers; then

(a) If $\mathfrak{R}(\tilde{A})>\mathfrak{R}(\tilde{B})$ then $\tilde{A} \succ \widetilde{B}$ i.e.,

$\operatorname{maximum}\{\tilde{A}, \tilde{B}\}=\tilde{A}$ and minimum $\{\tilde{A}, \tilde{B}\}=\widetilde{B}$

(b) If $\mathfrak{R}(\tilde{A})<\Re(\tilde{B})$ then $\tilde{A} \prec \tilde{B}$ i.e., $\operatorname{maximum}\{\tilde{A}, \tilde{B}\}=\tilde{B}$ and minimum $\{\tilde{A}, \tilde{B}\}=\tilde{A}$

(c) If $\mathfrak{R}(\tilde{A})=\mathfrak{R}(\tilde{B})$ then $\tilde{A}=\tilde{B}$

\subsection{Some existing ranking formulae for comparing fuzzy numbers}

Ranking formulae used in some existing ranking approaches $[21,17,15,7,23,8,3,25,2]$ for comparing $L R$ fuzzy numbers and $L R$ flat fuzzy numbers are shown in Table 1. 
Table 1: Ranking formulae used in some existing ranking approaches

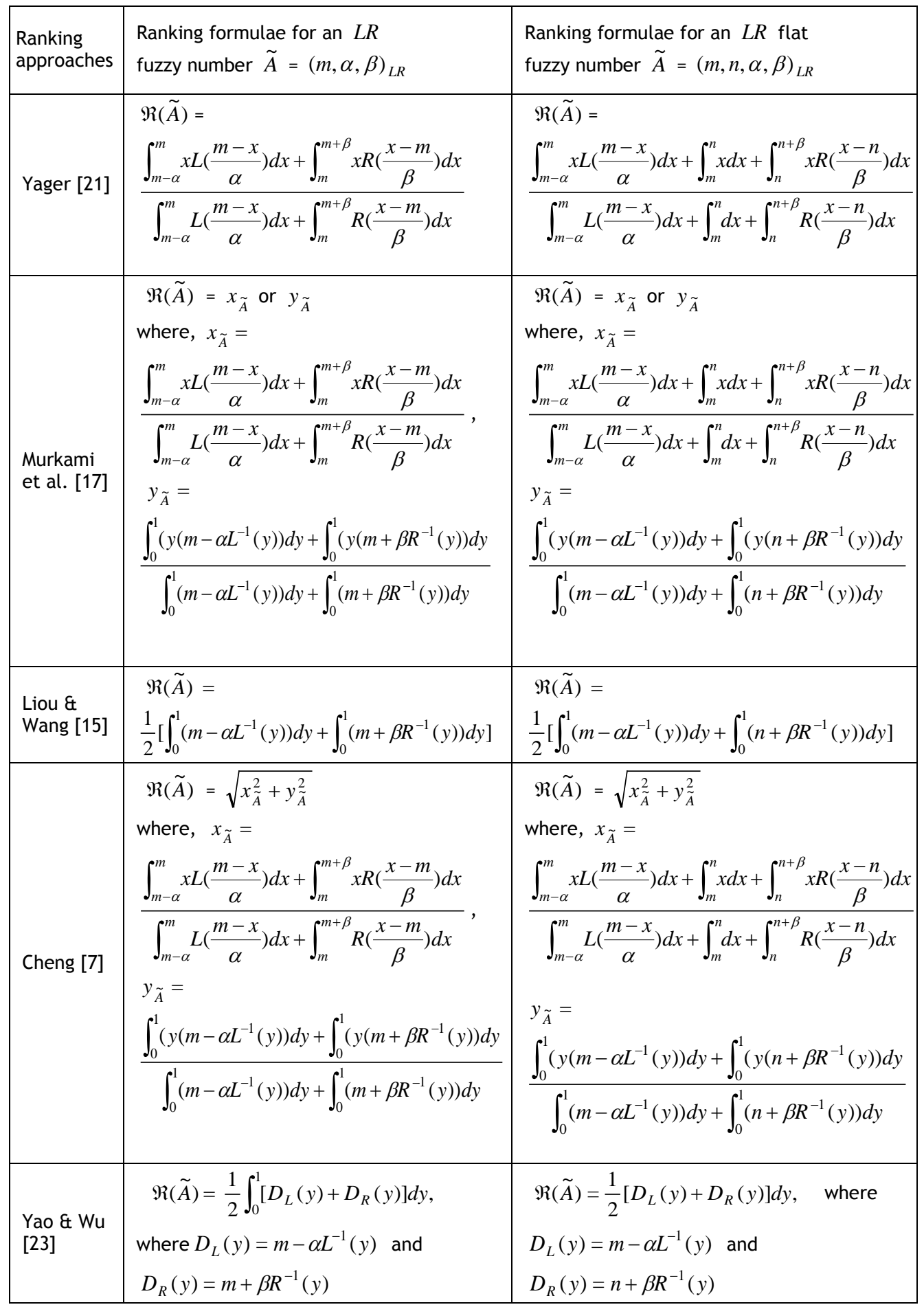

93 


\begin{tabular}{|c|c|c|}
\hline $\begin{array}{l}\text { Chu \& } \\
\text { Tsao [8] }\end{array}$ & $\begin{array}{l}\Re(A)=x_{\tilde{A}} \cdot y_{\tilde{A}} \quad \text { where, } x_{\tilde{A}}= \\
\frac{\int_{m-\alpha}^{m} x L\left(\frac{m-x}{\alpha}\right) d x+\int_{m}^{m+\beta} x R\left(\frac{x-m}{\beta}\right) d x}{\int_{m-\alpha}^{m} L\left(\frac{m-x}{\alpha}\right) d x+\int_{m}^{m+\beta} R\left(\frac{x-m}{\beta}\right) d x}, \\
y_{\tilde{A}}= \\
\frac{\int_{0}^{1}\left(y\left(m-\alpha L^{-1}(y)\right) d y+\int_{0}^{1}\left(y\left(m+\beta R^{-1}(y)\right) d y\right.\right.}{\int_{0}^{1}\left(m-\alpha L^{-1}(y)\right) d y+\int_{0}^{1}\left(m+\beta R^{-1}(y)\right) d y}\end{array}$ & $\begin{array}{l}\Re(A)=x_{\tilde{A}} \cdot y_{\tilde{A}} \text { where, } x_{\tilde{A}}= \\
\frac{\int_{m-\alpha}^{m} x L\left(\frac{m-x}{\alpha}\right) d x+\int_{m}^{n} x d x+\int_{n}^{n+\beta} x R\left(\frac{x-n}{\beta}\right) d x}{\int_{m-\alpha}^{m} L\left(\frac{m-x}{\alpha}\right) d x+\int_{m}^{n} d x+\int_{n}^{n+\beta} R\left(\frac{x-n}{\beta}\right) d x} \\
y_{\tilde{A}}= \\
\frac{\int_{0}^{1}\left(y\left(m-\alpha L^{-1}(y)\right) d y+\int_{0}^{1}\left(y\left(n+\beta R^{-1}(y)\right) d y\right.\right.}{\int_{0}^{1}\left(m-\alpha L^{-1}(y)\right) d y+\int_{0}^{1}\left(n+\beta R^{-1}(y)\right) d y}\end{array}$ \\
\hline $\begin{array}{l}\text { Asady \& } \\
\text { Zendeh- } \\
\text { nam [3] }\end{array}$ & $\begin{array}{l}\mathfrak{R}(\tilde{A})=\frac{1}{2} \int_{0}^{1}(\underline{A}(r)+\bar{A}(r)) d r, \text { where, } \\
\underline{A}(r)=m-\alpha L^{-1}(r) \text { and } \\
\bar{A}(r)=m+\beta R^{-1}(r)\end{array}$ & $\begin{array}{l}\Re(\tilde{A})=\frac{1}{2} \int_{0}^{1}(\underline{A}(r)+\bar{A}(r)) d r, \text { where } \\
\underline{A}(r)=m-\alpha L^{-1}(r) \text { and } \\
\bar{A}(r)=n+\beta R^{-1}(r)\end{array}$ \\
\hline $\begin{array}{l}\text { Zhao \& } \\
\text { Liu [25] }\end{array}$ & $\begin{array}{l}\Re(\tilde{A})= \\
\frac{1}{2} \mu_{\tilde{A}}(x)\left[\left|x_{\tilde{A}}\right|+\left|y_{\tilde{A}}\right|+\left|x_{\tilde{A}} \cdot y_{\tilde{A}}\right|\right] \\
\text { where, } \quad x_{\tilde{A}}= \\
\frac{\int_{m-\alpha}^{m} x L\left(\frac{m-x}{\alpha}\right) d x+\int_{m}^{m+\beta} x R\left(\frac{x-m}{\beta}\right) d x}{\int_{m-\alpha}^{m} L\left(\frac{m-x}{\alpha}\right) d x+\int_{m}^{m+\beta} R\left(\frac{x-m}{\beta}\right) d x}, \\
y_{\tilde{A}}= \\
\frac{\int_{0}^{1} y\left[\left(m+\beta R^{-1}(y)\right)-\left(m-\alpha L^{-1}(y)\right)\right] d y}{\int_{0}^{1}\left[\left(m+\beta R^{-1}(y)\right)-\left(m-\alpha L^{-1}(y)\right)\right] d y}, \\
\mu_{\tilde{A}}(x)\left\{\begin{array}{l}1 \quad x \geq 0 \\
-1 \quad x<0\end{array}\right.\end{array}$ & $\begin{array}{l}\Re(\tilde{A})=\frac{1}{2} \mu_{\tilde{A}}(x)\left[\left|x_{\tilde{A}}\right|+\left|y_{\tilde{A}}\right|+\left|x_{\tilde{A}} \cdot y_{\tilde{A}}\right|\right] \\
\text { where, } \quad x_{\tilde{A}}= \\
\frac{\int_{m-\alpha}^{m} x L\left(\frac{m-x}{\alpha}\right) d x+\int_{m}^{n} x d x+\int_{n}^{n+\beta} x R\left(\frac{x-n}{\beta}\right) d x}{\int_{m-\alpha}^{m} L\left(\frac{m-x}{\alpha}\right) d x+\int_{m}^{n} d x+\int_{n}^{n+\beta} R\left(\frac{x-n}{\beta}\right) d x} \\
y_{\tilde{A}}= \\
\frac{\int_{0}^{1} y\left[\left(n+\beta R^{-1}(y)\right)-\left(m-\alpha L^{-1}(y)\right)\right] d y}{\int_{0}^{1}\left[\left(n+\beta R^{-1}(y)\right)-\left(m-\alpha L^{-1}(y)\right)\right] d y}, \\
\mu_{\tilde{A}}^{1}(x) \begin{cases}1 & x \geq 0 \\
-1 & x<0\end{cases} \end{array}$ \\
\hline $\begin{array}{l}\text { Abbas- } \\
\text { bandy \& } \\
\text { Hajjari } \\
{[2]}\end{array}$ & $\begin{array}{r}\Re(\tilde{A})=\frac{1}{2}\left[\int_{0}^{1}\left(\left(m-\alpha L^{-1}(y)\right)+\right.\right. \\
\left.\left.\left(m+\beta R^{-1}(y)\right)+2 m\right) d y\right]\end{array}$ & $\begin{aligned} \mathfrak{R}(\tilde{A})= & \frac{1}{2}\left[\int_{0}^{1}\left(\left(m-\alpha L^{-1}(y)\right)+\right.\right. \\
& \left.\left.\left(n+\beta R^{-1}(y)\right)+m+n\right) d y\right]\end{aligned}$ \\
\hline
\end{tabular}

\subsection{Farhadinia ranking approach}

In this section, the existing ranking approach [9] for comparing $L R$ flat fuzzy numbers is presented.

Let $\tilde{A}=\left(m_{1}, n_{1}, \alpha_{1}, \beta_{1}\right)_{L R}$ and $\tilde{B}=\left(m_{2}, n_{2}, \alpha_{2}, \beta_{2}\right)_{L R}$ be two $L R$ flat fuzzy numbers;' then use the following steps to compare $\tilde{A}$ and $\widetilde{B}$ :

Step 1 Find $C(\tilde{A})=\inf \left\{x \in \operatorname{Supp}(\tilde{A}): \mu_{\tilde{A}}(x)=1\right\}=m_{1}$ and $C(\tilde{B})=\inf \{x \in \operatorname{Supp}(\tilde{B}):$

$$
\left.\mu_{\tilde{B}}(x)=1\right\}=m_{2}
$$

Case (i) If $C(\tilde{A})>C(\tilde{B})$ then $\tilde{A} \succ \tilde{B}$

Case (ii) If $C(\tilde{A})<C(\tilde{B})$ then $\tilde{A} \prec \tilde{B}$ 
Case (iii) If $C(\tilde{A})=C(\tilde{B})$ then go to Step 2 .

Step 2 Find $L(\tilde{A})=\inf \operatorname{Supp}(\tilde{A})=m_{1}-\alpha_{1}$ and $L(\tilde{B})=\inf \operatorname{Supp}(\tilde{B})=m_{2}-\alpha_{2}$

Case (i) If $L(\tilde{A})>L(\tilde{B})$ then $\tilde{A} \succ \tilde{B}$

Case (ii) If $L(\tilde{A})<L(\tilde{B})$ then $\tilde{A} \prec \widetilde{B}$

Case (iii) If $L(\tilde{A})=L(\tilde{B})$ then go to Step 3 .

Step 3 Find $W(\tilde{A})=|\operatorname{Supp}(\tilde{A})|=n_{1}-m_{1}+\alpha_{1}+\beta_{1}$ and $W(\tilde{B})=|\operatorname{Supp}(\tilde{B})|=$ $n_{2}-m_{2}+\alpha_{2}+\beta_{2}$

Case (i) If $W(\tilde{A})>W(\tilde{B})$ then $\tilde{A} \succ \tilde{B}$

Case (ii) If $W(\tilde{A})<W(\tilde{B})$ then $\tilde{A} \prec \tilde{B}$

Case (iii) If $W(\tilde{A})=W(\tilde{B})$ then go to Step 4 .

Step 4 Find $S(\tilde{A})=\int \mu_{\tilde{A}}(x) d x=n_{1}-m_{1}+\alpha_{1} \int_{0}^{1} L^{-1}(\lambda) d \lambda+\beta_{1} \int_{0}^{1} R^{-1}(\lambda) d \lambda$ and

$$
S(\tilde{B})=\int \mu_{\tilde{B}}(x) d x=n_{2}-m_{2}+\alpha_{2} \int_{0}^{1} L^{-1}(\lambda) d \lambda+\beta_{2} \int_{0}^{1} R^{-1}(\lambda) d \lambda
$$

Case (i) If $S(\tilde{A})>S(\tilde{B})$ then $\tilde{A} \succ \widetilde{B}$

Case (ii) If $S(\tilde{A})<S(\tilde{B})$ then $\tilde{A} \prec \tilde{B}$

Case (iii) If $S(\tilde{A})=S(\tilde{B})$ then $\tilde{A}=\tilde{B}$

Remark 1: For an $L R$ flat fuzzy number $\tilde{A}=(m, n, \alpha, \beta)_{L R}$

$$
S(\tilde{A})=\int \mu_{\tilde{A}}(x) d x=\int_{m-\alpha}^{m} L\left(\frac{m-x}{\alpha}\right) d x+\int_{m}^{n} d x+\int_{n}^{n+\beta} R\left(\frac{x-n}{\beta}\right) d x=n-m+\alpha \int_{0}^{1} L^{-1}(\lambda) d \lambda+\beta \int_{0}^{1} R^{-1}(\lambda) d \lambda
$$

\section{SHORTCOMINGS OF EXISTING RANKING APPROACHES}

There are several fuzzy critical path methods for solving fuzzy critical path problems in which ranking approaches are used to compare fuzzy numbers. In this section, it is shown that the results of the fuzzy critical path problem chosen in Example 3.1, and obtained by using the different existing fuzzy critical path methods $[18,22,4,13,14,16,12,10,5,6$, 19] with different existing ranking approaches [21, 17, 15, 7, 23, 8, 3, 25, 2], are not appropriate according to real life situations.

Example 3.1 Find the fuzzy critical path and maximum total fuzzy completion time of the project shown in Figure 1, in which the fuzzy time duration of activity $(i, j)$ is represented by $L R$ fuzzy numbers $\tilde{t}_{i j}$ with $L(x)=R(x)=\max \{0,1-x\}$ as follows:

$$
\tilde{t}_{12}=(1,0.5,0.5)_{L R}, \tilde{t}_{23}=(1,1,1)_{L R}, \tilde{t}_{24}=(2,0.5,0.5)_{L R}, \tilde{t}_{34}=(1,0.5,0.5)_{L R}
$$

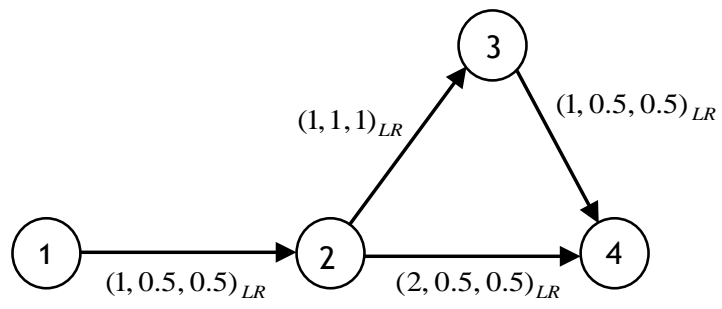

Figure 1: Project network of the illustrated Example 3.1 


\subsection{Results of the problem chosen in Example 3.1}

The results of the fuzzy critical path problem chosen in Example 3.1, and obtained by using different existing fuzzy critical path methods [18, 22, 4, 13, 14, 16, 12, 10, 5, 6, 19] with different existing ranking approaches $[21,17,15,7,23,8,3,25,2,9]$ are shown in Table 2.

Table 2: Results of Example 3.1 obtained by using existing fuzzy critical path methods with existing ranking approaches

\begin{tabular}{|c|c|c|}
\hline \multirow{3}{*}{$\begin{array}{l}\text { Existing ranking } \\
\text { approaches }\end{array}$} & \multicolumn{2}{|c|}{$\begin{array}{l}\text { Results of fuzzy critical path problem obtained by using different existing } \\
\text { fuzzy critical path methods }[18,22,4,13,14,16,12,10,5,6,19]\end{array}$} \\
\hline & \multicolumn{2}{|r|}{ Example 3.1} \\
\hline & Fuzzy critical path & Maximum total fuzzy project completion time $(\tilde{T})$ \\
\hline Yager [21] & $\begin{array}{l}1 \Rightarrow 2 \Rightarrow 3 \Rightarrow 4 \\
1 \Rightarrow 2 \Rightarrow 4\end{array}$ & $\begin{array}{l}(3,2,2)_{L R}, \Re(\tilde{T})=3 \\
(3,1,1)_{L R}, \Re(\tilde{T})=3\end{array}$ \\
\hline Murkami et al.[17] & $\begin{aligned} 1 \Rightarrow 2 \Rightarrow 3 \Rightarrow 4 & \Rightarrow \\
1 & \Rightarrow 2 \Rightarrow 4\end{aligned}$ & $\begin{array}{l}(3,2,2)_{L R}, x_{\tilde{T}}=3, y_{\tilde{T}}=0.5 \\
(3,1,1)_{L R}, x_{\tilde{T}}=3, y_{\tilde{T}}=0.5\end{array}$ \\
\hline Liou \& Wang [15] & $\begin{array}{c}1 \Rightarrow 2 \Rightarrow 3 \Rightarrow 4 \\
1 \Rightarrow 2 \Rightarrow 4\end{array}$ & $\begin{array}{c}(3,2,2)_{L R}, \mathfrak{R}(\tilde{T})=3 \\
(31,1)_{L R}, \mathfrak{R}(\tilde{T})=3\end{array}$ \\
\hline Cheng [7] & $\begin{array}{c}1 \Rightarrow 2 \Rightarrow 3 \Rightarrow 4 \\
1 \Rightarrow 2 \Rightarrow 4\end{array}$ & $\begin{array}{l}(3,2,2)_{L R}, \Re(\tilde{T})=3.041 \\
(3,1,1)_{L R}, \Re(\tilde{T})=3.041\end{array}$ \\
\hline Yao \& Wu [23] & $\begin{array}{c}1 \Rightarrow 2 \Rightarrow 3 \Rightarrow 4 \\
1 \Rightarrow 2 \Rightarrow 4\end{array}$ & $\begin{array}{l}(3,2,2)_{L R}, \mathfrak{R}(\tilde{T})=3 \\
(3,1,1)_{L R}, \Re(\tilde{T})=3\end{array}$ \\
\hline Chu \& Tsao [8] & $\begin{array}{c}1 \Rightarrow 2 \Rightarrow 3 \Rightarrow 4 \\
1 \Rightarrow 2 \Rightarrow 4\end{array}$ & $\begin{array}{l}(3,2,2)_{L R}, \Re(\tilde{T})=1.5 \\
(3,1,1)_{L R}, \Re(\tilde{T})=1.5\end{array}$ \\
\hline $\begin{array}{l}\text { Asady \& } \\
\text { Zendehnam [3] }\end{array}$ & $\begin{array}{c}1 \Rightarrow 2 \Rightarrow 3 \Rightarrow 4 \\
1 \Rightarrow 2 \Rightarrow 4\end{array}$ & $\begin{array}{c}(3,2,2)_{L R}, \mathfrak{R}(\tilde{T})=3 \\
(3,1,1)_{L R}, \Re(\tilde{T})=3\end{array}$ \\
\hline Zhao \& Liu [25] & $\begin{array}{c}1 \Rightarrow 2 \Rightarrow 3 \Rightarrow 4 \\
1 \Rightarrow 2 \Rightarrow 4\end{array}$ & $\begin{array}{l}(3,2,2)_{L R}, \Re(\tilde{T})=2.167 \\
(3,1,1)_{L R}, \Re(\tilde{T})=2.167\end{array}$ \\
\hline $\begin{array}{l}\text { Abbasbandy \& } \\
\text { Hajjari [2] }\end{array}$ & $\begin{array}{c}1 \Rightarrow 2 \Rightarrow 3 \Rightarrow 4 \\
1 \Rightarrow 2 \Rightarrow 4\end{array}$ & $\begin{array}{l}(3,1,1)_{L R}, \Re(\tilde{T})=6 \\
(3,1,1)_{L R}, \Re(\tilde{T})=6\end{array}$ \\
\hline Farhadinia [9] & $1 \Rightarrow 2 \Rightarrow 4$ & $(3,1,1)_{L R}, L(\tilde{T})=2$ \\
\hline
\end{tabular}

It is obvious from the results shown in Table 2 that, on solving the fuzzy critical path problem chosen in Example 3.1 by applying the different existing fuzzy critical path methods $[18,22,4,13,14,16,12,10,5,6,19]$ with existing ranking approaches $[21,17$, $15,7,23,8,3,25,2]$, more than one fuzzy critical path is obtained, and the maximum total fuzzy project completion time corresponding to different fuzzy critical paths is different - so their physical interpretation will also be different. But in the literature [20] it is pointed out that if, on solving a project network problem there is more than one critical path, then the maximum total completion time of the project should be the same, corresponding to all the critical paths. So the results obtained by using existing fuzzy critical path methods $[18,22,4,13,14,16,12,10,5,6,19]$ with existing ranking approaches $[21,17,15,7,23,8,3,25,2]$, shown in Table 2, are not appropriate according to real life situations. 
Since the results of the fuzzy critical path problem chosen in Example 3.1 and obtained by using the existing fuzzy critical path methods [18, 22, 4, 13, 14, 16, 12, 10, 5, 6, 19] with an existing ranking approach [9] are appropriate according to real life situations, therefore, to show the shortcomings of the existing ranking approach [9], a fuzzy critical path problem (Example 3.2) is solved by using existing fuzzy critical path methods $[18,22,4,13,14,16$, $12,10,5,6,19]$ with the existing ranking approach [9].

Example 3.2 Find the fuzzy critical path and maximum total fuzzy completion time of the project shown in Figure 2, in which the fuzzy time duration of activity $(i, j)$ is represented by $L R$ flat fuzzy numbers $\tilde{t}_{i j}$ with $L(x)=\max \left\{0,1-x^{2}\right\}$ and $R(x)=e^{-|x|}$ as follows:

$$
\begin{aligned}
& \tilde{t}_{12}=(2,2.3,0.6,0.8)_{L R}, \tilde{t}_{23}=(5,6,1,1.2)_{L R}, \tilde{t}_{34}=(7,7.8,1,1.1)_{L R}, \tilde{t}_{35}=(4,4.5,0.7,2.7)_{L R}, \\
& \tilde{t}_{46}=(2,4.2,0.7,1.8)_{L R}, \tilde{t}_{56}=(5,5.5,1,2.2)_{L R}, \tilde{t}_{47}=(5,9.6,1.1,1.3)_{L R}, \tilde{t}_{67}=(3,3.4,0.4,1.5)_{L R}, \\
& \tilde{t}_{78}=(6,6.3,0.3,0.6)_{L R}
\end{aligned}
$$

Find the fuzzy critical path and maximum total fuzzy completion time of the project.

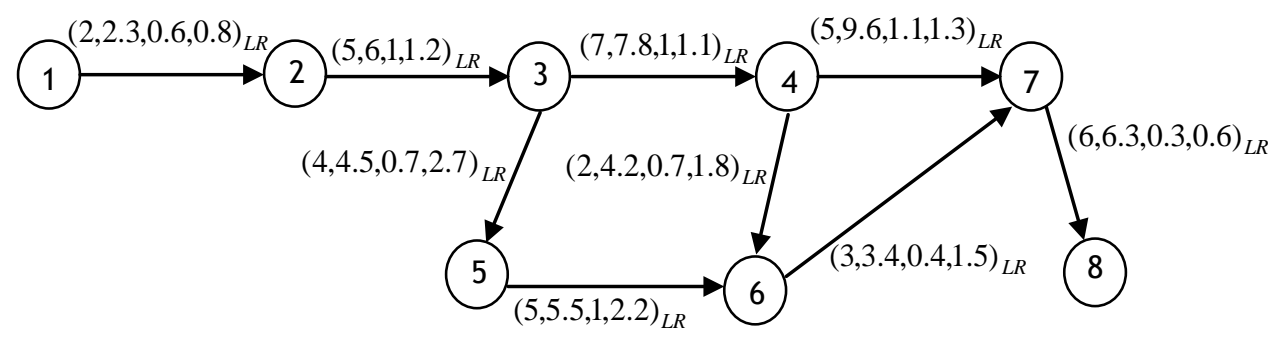

Figure 2: Project network of the illustrated Example 3.2

\subsection{Results of the problem chosen in Example 3.2}

The results of the fuzzy critical path problem chosen in Example 3.2, and obtained by using different existing fuzzy critical path methods [18, 22, 4, 13, 14, 16, 12, 10, 5, 6, 19] with the existing ranking approach [9] are shown in Table 4.

Table 4: Results of Example 3.2 obtained by using existing fuzzy critical path methods with Farhadinia ranking approach

\begin{tabular}{|c|c|c|}
\hline \multirow{3}{*}{ Example } & \multicolumn{2}{|c|}{$\begin{array}{l}\text { Results of fuzzy critical path problems obtained by using different existing fuzzy critical } \\
\text { methods [18, 22, 4, 13,14,16,12,10,5, 6, 19] with the Farhadinia ranking approach [9] }\end{array}$} \\
\cline { 2 - 3 } & \multicolumn{1}{|c|}{ Fuzzy critical path } & $\begin{array}{c}\text { Maximum total fuzzy project completion } \\
\text { time }(\tilde{T})\end{array}$ \\
\hline \multirow{3}{*}{3.2} & $1 \Rightarrow 2 \Rightarrow 3 \Rightarrow 4 \Rightarrow 6 \Rightarrow 7 \Rightarrow 8$ & $(25,30,4,7)_{L R}, S(\tilde{T})=14.667$ \\
& $1 \Rightarrow 2 \Rightarrow 3 \Rightarrow 5 \Rightarrow 6 \Rightarrow 7 \Rightarrow 8$ & $(25,28,4,9)_{L R}, S(\tilde{T})=14.667$ \\
& $1 \Rightarrow 2 \Rightarrow 3 \Rightarrow 4 \Rightarrow 7 \Rightarrow 8$ & $(25,32,4,5)_{L R}, S(\tilde{T})=14.667$ \\
\hline
\end{tabular}

It is obvious from the results shown in Table 4 that, on solving the fuzzy critical path problem chosen in Example 3.2 by using the existing fuzzy critical path methods with the existing ranking approach [9], three different $L R$ flat fuzzy numbers - $(25,28,4,9)_{L R}$, $(25,30,4,7)_{L R}$ and $(25,32,4,5)_{L R}$, representing the maximum total fuzzy completion time of the same project - are obtained; and this is not appropriate according to real life situations. 
Remark 2: In Section 3, the shortcomings of some important ranking approaches are pointed out. The same shortcomings can also be found in other existing ranking approaches that are not discussed in this paper.

\section{PROPOSED MEHAR RANKING APPROACH}

On the basis of the results discussed in Section 3 , it can be concluded that none of the existing ranking approaches $[21,17,15,7,23,8,3,25,2,9]$ with existing fuzzy critical path methods $[18,22,4,13,14,16,12,10,5,6,19]$ can be used to find the appropriate results of such fuzzy critical path problems in which the fuzzy activity time of all the activities is represented by $L R$ flat fuzzy numbers.

To overcome the shortcomings of existing ranking approaches $[21,17,15,7,23,8,3,25,2$, 9], a new ranking approach - the Mehar ranking approach - is proposed for comparing $L R$ flat fuzzy numbers. Since the triangular fuzzy numbers, trapezoidal fuzzy numbers, and $L R$ fuzzy numbers are particular cases of $L R$ flat fuzzy numbers, the Mehar ranking approach can also be used for comparing these fuzzy numbers.

Let $\tilde{A}=\left(m_{1}, n_{1}, \alpha_{1}, \beta_{1}\right)_{L R}$ and $\tilde{B}=\left(m_{2}, n_{2}, \alpha_{2}, \beta_{2}\right)_{L R}$ be two $L R$ flat fuzzy numbers; then use the following steps to compare $\tilde{A}$ and $\widetilde{B}$ :

Step 1 Find $\operatorname{Me}(\tilde{A})=\frac{1}{2}\left[\int_{0}^{1} m_{1} d \lambda-\int_{0}^{1} \alpha_{1} L^{-1}(\lambda) d \lambda+\int_{0}^{1} n_{1} d \lambda+\int_{0}^{1} \beta_{1} R^{-1}(\lambda) d \lambda\right]$

$$
\text { and } \operatorname{Me}(\tilde{B})=\frac{1}{2}\left[\int_{0}^{1} m_{2} d \lambda-\int_{0}^{1} \alpha_{2} L^{-1}(\lambda) d \lambda+\int_{0}^{1} n_{2} d \lambda+\int_{0}^{1} \beta_{2} R^{-1}(\lambda) d \lambda\right]
$$

Case (i) If $\operatorname{Me}(\tilde{A})>\operatorname{Me}(\tilde{B})$ then $\tilde{A} \succ \widetilde{B}$

Case (ii) If $\operatorname{Me}(\tilde{A})<\operatorname{Me}(\tilde{B})$ then $\tilde{A} \prec \widetilde{B}$

Case (iii) If $\operatorname{Me}(\tilde{A})=\operatorname{Me}(\tilde{B})$ then go to Step 2 .

Step 2 Find $H(\tilde{A})=\frac{1}{2}\left[\int_{0}^{1} m_{1} d \lambda+\int_{0}^{1} n_{1} d \lambda\right]$ and $H(\tilde{B})=\frac{1}{2}\left[\int_{0}^{1} m_{2} d \lambda+\int_{0}^{1} n_{2} d \lambda\right]$

Case (i) If $H(\tilde{A})>H(\tilde{B})$ then $\tilde{A} \succ \widetilde{B}$

Case (ii) If $H(\tilde{A})<H(\tilde{B})$ then $\tilde{A} \prec \tilde{B}$

Case (iii) If $H(\tilde{A})=H(\tilde{B})$ then go to Step 3 .

Step 3 Find $A(\tilde{A})=\int_{0}^{1} n_{1} d \lambda+\int_{0}^{1} \beta_{1} R^{-1}(\lambda) d \lambda-\int_{0}^{1} m_{1} d \lambda+\int_{0}^{1} \alpha_{1} L^{-1}(\lambda) d \lambda$

$$
\text { and } A(\tilde{B})=\int_{0}^{1} n_{2} d \lambda+\int_{0}^{1} \beta_{2} R^{-1}(\lambda) d \lambda-\int_{0}^{1} m_{2} d \lambda+\int_{0}^{1} \alpha_{2} L^{-1}(\lambda) d \lambda
$$

Case (i) If $A(\tilde{A})>A(\tilde{B})$ then $\tilde{A} \succ \widetilde{B}$

Case (ii) If $A(\tilde{A})<A(\tilde{B})$ then $\tilde{A} \prec \tilde{B}$

Case (iii) If $A(\tilde{A})=A(\tilde{B})$ then go to Step 4 .

Step 4 Find $R(\tilde{A})=\int_{0}^{1} \alpha_{1} L^{-1}(\lambda) d \lambda$ (or $S(\tilde{A})=\int_{0}^{1} \beta_{1} R^{-1}(\lambda) d \lambda$ )

$$
\text { and } R(\tilde{B})=\int_{0}^{1} \alpha_{2} L^{-1}(\lambda) d \lambda \quad \text { (or } S(\tilde{B})=\int_{0}^{1} \beta_{2} R^{-1}(\lambda) d \lambda \text { ) }
$$

Case (i) If $R(\tilde{A})>R(\tilde{B}) \quad($ or $S(\tilde{A})>S(\tilde{B})$ ) then $\tilde{A} \succ \tilde{B}$

Case (ii) If $R(\tilde{A})<R(\tilde{B}) \quad$ (or $S(\tilde{A})<S(\tilde{B})$ ) then $\tilde{A} \prec \tilde{B}$

Case (iii) If $R(\tilde{A})=R(\tilde{B}) \quad$ (or $S(\tilde{A})=S(\tilde{B})$ ) then $\tilde{A}=\tilde{B}$ 


\section{SOME IMPORTANT RESULTS}

In this section, some important results that are used to propose the Mehar ranking approach for comparing $L R$ flat fuzzy numbers are proved.

Proposition 5.1 Let $\tilde{A}=\left(m_{1}, n_{1}, \alpha_{1}, \beta_{1}\right)_{L R}$ and $\tilde{B}=\left(m_{2}, n_{2}, \alpha_{2}, \beta_{2}\right)_{L R}$ be two $L R$ flat fuzzy numbers, such that (i) $\operatorname{Me}(\tilde{A})=\operatorname{Me}(\tilde{B})$ $R(\tilde{A})=R(\tilde{B}) \quad($ or $S(\tilde{A})=S(\tilde{B}))$; then
$\tilde{A}=\tilde{B}$.

(ii) $H(\tilde{A})=H(\tilde{B})$

(iii) $A(\tilde{A})=A(\tilde{B})$ (iv)

Proof: Straightforward

Proposition 5.2 Let $\tilde{A}=\left(m_{1}, n_{1}, \alpha_{1}, \beta_{1}\right)_{L R}$ and $\tilde{B}=\left(m_{2}, n_{2}, \alpha_{2}, \beta_{2}\right)_{L R}$ be two $L R$ flat fuzzy numbers such that (i) $\operatorname{Me}(\tilde{A})=\operatorname{Me}(\tilde{B})$

(ii) $H(\tilde{A})=H(\tilde{B})$

(iii) $A(\tilde{A})=A(\tilde{B})$; then
(a) $R(\tilde{A})>R(\tilde{B})$ iff $S(\tilde{A})>S(\tilde{B})$
(b) $R(\tilde{A})<R(\tilde{B})$ iff $S(\tilde{A})<S(\tilde{B})$
(c) $R(\tilde{A})=R(\tilde{B})$ iff $S(\tilde{A})=S(\tilde{B})$

Proof: (i) $\operatorname{Me}(\tilde{A})=\operatorname{Me}(\tilde{B})$

$$
\begin{aligned}
\Rightarrow & \frac{1}{2}\left[\int_{0}^{1} m_{1} d \lambda-\int_{0}^{1} \alpha_{1} L^{-1}(\lambda) d \lambda+\int_{0}^{1} n_{1} d \lambda+\int_{0}^{1} \beta_{1} R^{-1}(\lambda) d \lambda\right]=\frac{1}{2}\left[\int_{0}^{1} m_{2} d \lambda-\int_{0}^{1} \alpha_{2} L^{-1}(\lambda) d \lambda+\int_{0}^{1} n_{2} d \lambda\right. \\
& +\int_{0}^{1} \beta_{2} R^{-1}(\lambda) d \lambda \\
\Rightarrow & m_{1}-\int_{0}^{1} \alpha_{1} L^{-1}(\lambda) d \lambda+n_{1}+\int_{0}^{1} \beta_{1} R^{-1}(\lambda) d \lambda=m_{2}-\int_{0}^{1} \alpha_{2} L^{-1}(\lambda) d \lambda+n_{2}+\int_{0}^{1} \beta_{2} R^{-1}(\lambda) d \lambda \\
\text { (ii) } & H(\tilde{A})=H(\tilde{B}) \\
& \Rightarrow \frac{1}{2}\left[\int_{0}^{1} m_{1} d \lambda+\int_{0}^{1} n_{1} d \lambda\right]=\frac{1}{2}\left[\int_{0}^{1} m_{2} d \lambda+\int_{0}^{1} n_{2} d \lambda\right] \\
& \Rightarrow m_{1}+n_{1}=m_{2}+n_{2}
\end{aligned}
$$

(iii) $A(\tilde{A})=A(\tilde{B})$

$$
\Rightarrow n_{1}+\int_{0}^{1} \beta_{1} R^{-1}(\lambda) d \lambda-m_{1}+\int_{0}^{1} \alpha_{1} L^{-1}(\lambda) d \lambda=n_{2}+\int_{0}^{1} \beta_{2} R^{-1}(\lambda) d \lambda-m_{2}+\int_{0}^{1} \alpha_{2} L^{-1}(\lambda) d \lambda
$$

(a) $R(\tilde{A})>R(\tilde{B})$

$$
\begin{aligned}
& \Leftrightarrow \int_{0}^{1} \alpha_{1} L^{-1}(\lambda) d \lambda>\int_{0}^{1} \alpha_{2} L^{-1}(\lambda) d \lambda \\
& \Leftrightarrow\left(\alpha_{1}-\alpha_{2}\right) \int_{0}^{1} L^{-1}(\lambda) d \lambda>0
\end{aligned}
$$

Subtracting (2) from (1)

$$
\left(\beta_{1}-\beta_{2}\right) \int_{0}^{1} R^{-1}(\lambda) d \lambda=\left(\alpha_{1}-\alpha_{2}\right) \int_{0}^{1} L^{-1}(\lambda) d \lambda
$$

Using (5) the equation (4) can be written as

$$
\begin{aligned}
& \Leftrightarrow\left(\beta_{1}-\beta_{2}\right) \int_{0}^{1} R^{-1}(\lambda) d \lambda>0 \\
& \Leftrightarrow \beta_{1} \int_{0}^{1} R^{-1}(\lambda) d \lambda>\beta_{2} \int_{0}^{1} R^{-1}(\lambda) d \lambda \\
& \Leftrightarrow S(\tilde{A})>S(\tilde{B})
\end{aligned}
$$

Similarly (b) and (c) can be easily proved. 


\section{ADVANTAGES OF THE MEHAR RANKING APPROACH OVER THE EXISTING RANKING APPROACHES}

The main advantage of the Mehar ranking approach over the existing ranking approaches $[21,17,15,7,23,8,3,25,2,9]$ is that, on solving the fuzzy critical path problem by using the different existing fuzzy critical path methods $[18,22,4,13,14,16,12,10,5,6,19]$ with existing ranking approaches $[21,17,15,7,23,8,3,25,2,9]$, more than one fuzzy number, representing the maximum total fuzzy project completion time, is obtained. As a result, there will be different interpretations for the maximum total fuzzy project completion time of the same project - which is not appropriate according to real life situations. However, by using the different existing fuzzy critical path methods with the Mehar ranking approach, a unique fuzzy number, representing the maximum total fuzzy project completion time, is obtained. Thus there will be a unique interpretation of the maximum total fuzzy completion time of the project.

To show the advantages of the Mehar ranking approach over existing ranking approaches $[21,17,15,7,23,8,3,25,2,9]$, the fuzzy critical path problems chosen in Examples 3.1 and 3.2 - for which more than one fuzzy number, representing the maximum total fuzzy project completion time is obtained - are solved by using existing fuzzy critical path methods with the Mehar ranking approach; and it is shown that by using existing fuzzy critical path methods with the Mehar ranking approach, a unique fuzzy number, representing the maximum total fuzzy project completion time, is obtained.

The results of the fuzzy critical path problems chosen in Examples 3.1 and 3.2, which were obtained by using different existing fuzzy critical path methods with the Mehar ranking approach, are shown in Table 5.

Table 5: Results of Example 3.1 and Example 3.2 obtained by using existing fuzzy critical path methods with the Mehar ranking approach

\begin{tabular}{|l|c|c|}
\hline \multirow{2}{*}{ Example } & \multicolumn{2}{|c|}{$\begin{array}{c}\text { Results of fuzzy critical path problems obtained by using different existing fuzzy critical } \\
\text { methods [18, 22, 4, 13,14,16,12,10,5, 6, 19] with the Mehar ranking approach }\end{array}$} \\
\cline { 2 - 3 } & Fuzzy critical path & Maximum total fuzzy project completion time $(\tilde{T})$ \\
\hline 3.1 & $1 \Rightarrow 2 \Rightarrow 3 \Rightarrow 4$ & $(3,2,2)_{L R}, A(\tilde{T})=2$ \\
\hline 3.2 & $1 \Rightarrow 2 \Rightarrow 3 \Rightarrow 4 \Rightarrow 7 \Rightarrow 8$ & $(25,32,4,5)_{L R}, H(\tilde{T})=28.5$ \\
\hline
\end{tabular}

It is obvious from the results shown in Table 2 that, if the fuzzy critical path problem in Example 3.1 is solved by using the existing fuzzy critical path methods [18, 22, 4, 13, 14, $16,12,10,5,6,19]$ with the existing ranking approach [9], then a unique fuzzy number, representing the maximum total fuzzy project completion time, is obtained. But it is also obvious from the results in Table 4 that, if the fuzzy critical path problem in Example 3.2 is solved by using the existing fuzzy critical path methods $[18,22,4,13,14,16,12,10,5,6$, 19] with the existing ranking approach [9], then more than one fuzzy number, representing the maximum total fuzzy project completion time, is obtained; and this is not appropriate according to real life situations. It is also obvious from the results in Table 5 that on solving both fuzzy critical path problems in Examples 3.1 and 3.2 by using the existing fuzzy critical path methods with the Mehar ranking approach, a unique fuzzy number representing the maximum total fuzzy project completion time is obtained, which is appropriate according to real life situations.

On the basis of these results, it can be suggested that it is better to use the existing fuzzy critical path methods with the Mehar ranking approach, rather than the existing fuzzy critical path methods with the existing ranking approaches $[21,17,15,7,23,8,3,25,2$, 9] to solvie the fuzzy critical path problems. 


\section{CONCLUSION AND FUTURE WORK}

Some fuzzy critical path problems have been chosen to show that it is not better to use the existing fuzzy critical path methods with existing ranking approaches to solve the fuzzy critical path problems. Instead, a new ranking approach, the Mehar ranking approach, is proposed for comparing LR flat fuzzy numbers. To show the advantage of the Mehar ranking approach over existing ranking approaches, identical fuzzy critical path problems are solved by using the existing fuzzy critical path methods with existing ranking approaches on the one hand, and by using the existing fuzzy critical path methods with the Mehar ranking approach on the other hand. It is shown that the results from the latter combination are better than those obtained from the former.

In future, the appropriate results of such real life problems, in which the existing ranking approaches are used to compare fuzzy numbers, can be obtained by using the proposed Mehar ranking approach.

\section{REFERENCES}

[1] Abbasbandy, S. \& Asady, B. 2006. Ranking of fuzzy numbers by sign distance, Information Sciences, 176, pp 2405-2416.

[2] Abbasbandy, S. \& Hajjari, T. 2009. A new approach for ranking of $L R$ flat fuzzy numbers, Computers and Mathematics with Applications, 57, pp 413-419.

[3] Asady, B. \& Zendehnam, A. 2007. Ranking fuzzy numbers by distance minimization, Applied Mathematical Modelling, 31, pp 2589-2598.

[4] Chanas, S. \& Zielinski, P. 2001. Critical path analysis in the network with fuzzy activity times, Fuzzy Sets and Systems, 122, pp 195-204.

[5] Chen, S.P. 2007. Analysis of critical paths in a project network with fuzzy activity times, European J ournal of Operational Research, 183, pp 442-459.

[6] Chen, S.P. \& Hsueh, Y.J. 2008. A simple approach to fuzzy critical path analysis in project networks, Applied Mathematical Modelling, 32, pp 1289-1297.

[7] Cheng, C.H. 1998. A new ranking approach for ranking fuzzy numbers by distance method, Fuzzy Sets and Systems, 95, pp 307-317.

[8] Chu, T.C. \& Tsao, C.T. 2002. Ranking fuzzy numbers with an area between the centroid point and original point, Computers and Mathematics with Applications, 43, pp 111-117.

[9] Farhadinia, B. 2009. Ranking fuzzy numbers based on lexicographical ordering, World Academy of Science, Engineering and Technology, 57, pp 1029-1032.

[10] Han, T.C., Chung, C.C. \& Liang, G.S. 2006. Application of fuzzy critical path method to airport's cargo ground operation systems, Journal of Marine Science and Technology, 14, pp 139-146.

[11] Jain, R. 1976. Decision-making in the presence of fuzzy variables, IEEE Transactions on Systems, Man and Cybernetics, 6, pp 698-703.

[12] Liang, G.S. \& Han, T.C. 2004. Fuzzy critical path for project network, Information and Management Sciences, 15, pp 29-40.

[13] Lin, F.T. 2002. Fuzzy critical path method based on statistical data, Proceedings IEEE International Conference on Fuzzy Systems, 2, pp 1245-1250.

[14] Lin, F.T. \& Yao, J.S. 2003. Fuzzy critical path method based on signed-distance ranking and statistical confidence-interval estimates, J ournal of Supercomputing, 24, pp 305-325.

[15] Liou, T.S. \& Wang, M.J. 1992. Ranking fuzzy numbers with integral value, Fuzzy Sets and Systems, 50, pp 247-255.

[16] Liu, S.T. 2003. Fuzzy activity times in critical path and project crashing problems, Cybernetics and Systems, 34, pp 161-172.

[17] Murakami, S., Maeda, S. \& Imamura, S. 1983. Fuzzy decision analysis on the development of centralized regional energy control system, Proceedings of IFAC Symposium on Fuzzy Information, Knowledge Representation and Decision Analysis, pp 363-368.

[18] Nasution, S.H. 1994. Fuzzy critical path method, IEEE Transactions on Systems, Man and Cybernetics, 24, pp 48-57.

[19] Shankar, N.R., Sireesha, V. \& Rao, P.B. 2010. An analytical method for finding critical path in a fuzzy project network, International J ournal of Contemporary Mathematical Sciences, 5, pp 953-962.

[20] Taha, H.A. 2003. Operations research: An introduction, Prentice-Hall, New Jersey.

[21] Yager, R.R. 1978. Ranking fuzzy subsets over the unit interval, Proceedings of the $17^{\text {th }}$ IEEE International Conference on Decision and Control, pp 1435-1437. 
[22] Yao, J.S. \& Lin, F.T. 2000. Fuzzy critical path method based on signed distance ranking of fuzzy numbers, IEEE Transactions on Systems, Man and Cybernetics - Part A: Systems and Humans, 30, pp 76-82.

[23] Yao, J.\& Wu, K. 2000. Ranking fuzzy numbers based on decomposition principle and signed distance, Fuzzy Sets and Systems, 116, pp 275-288.

[24] Zadeh, L.A. 1965. Fuzzy sets, Information and Control, 8, pp 338-353.

[25] Zhao, J. \& Liu, Q.S. 2008. Ranking fuzzy numbers based on the centroids of fuzzy numbers, Fuzzy Systems and Mathematics, 22, pp 142-146. 